\title{
Calcium-Transporting ATPase Type 2C Member 2
}

National Cancer Institute

\section{Source}

National Cancer Institute. Calcium-Transporting ATPase Type 2CMember 2. NCI

Thesaurus. Code C94687.

Calcium-transporting AT Pase type 2C member 2 (946 aa, $103 \mathrm{kDa}$ ) is encoded by the human AT P2C2 gene. This protein plays a role in active transport of calcium ions. 